\title{
USO DE ÁRBOLES DE DECISIÓN PARA LA ESTIMACIÓN ESTADÍSTICA
}

Carlos Eduardo Valdivieso Taborga, Roberto Valdivieso Castellón y Oscar Álvaro Valdivieso Taborga

\section{RESUMEN}

El artículo muestra el desarrollo de árboles de decisión para facilitar al investigador o profesional la elección del intervalo de confianza adecuado, a fin de estimar parámetros, como la media, proporción o varianza poblacionales o la diferencia de medias, proporciones o cociente de varianzas. Esta elección es compleja, ya que depende de muchos factores, entre los cuales están: el número de muestras comparadas, la normalidad de las poblaciones de las que provienen las muestras, el tamaño de las muestras, el conocimiento de las varianzas poblacionales, la dependencia de las muestras y la igualdad de las varianzas poblacionales.

Se han configurado 4 árboles de decisión tomando en cuenta estos factores y otras consideraciones teóricas y empíricas: Un árbol general que ayuda a establecer el intervalo de confianza adecuado, otro para estimar la media poblacional, otro para estimar la diferencia de medias y el último para la proporción o diferencia de proporciones. Se exponen dos ejemplos para ilustrar su fácil aplicación y se dan conclusiones e implicaciones de su uso.

Palabras Clave: Estadística Inferencial, Árboles de Decisión, Estimación Estadística, Intervalos de Confianza, Estadística Educacional. 